\title{
A OBjetividade COMO CRitério DE Cientificidade na Antropologia
}

Christina de Rezende Rubim

Tendo como pressuposto de todas as ciências - e tomando por base, neste caso específico, a Antropologia - a busca da verdade, e sendo a questão da objetividade concepção fundamental para o entendimento desta busca e da própria existência científica, procuraremos analisar este conceito em especial e outros mais que estejam próximos a ele e tenham importância para a sua compreensão.

Pensaremos a categoria da objetividade através de um autor consagrado na Antropologia brasileira contemporânea, Roberto Cardoso de Oliveira, tomando como base a sua Matriz Disciplinar ${ }^{1}$ e, portanto, dialogando com autores como Durkheim, EvansPritchard, Boas, Geertz entre outros sem, no entanto, nos prender aos autores exemplares a cada paradigma da citada Matriz Disciplinar. Nosso objetivo neste ensaio é, portanto, fazer o contraponto entre diferentes autores no que diz respeito à objetividade proposta por cada um deles.

Nesse rastreamento, nosso objetivo não é somente constatar o privilegiamento ou não da objetividade científica nos paradigmas

${ }^{1}$ Veja o quadro das páginas 143-144.

Temáticas, Campinas, 2(4):141-180, jul./dez. 1994 
como também ensaiar algumas proposições, tais como o fazer antropológico, como ele vem sendo historicamente entendido.

Nesta perspectiva é que colocamos algumas indagações que, para nós, tem importância serem analisadas, questionadas e relativamente esgotadas. A objetividade é inerente ao pensamento científico nas Ciências Sociais? A verdade objetiva pode ser relativizada segundo os paradigmas e consideradas todas elas como válidas, ou ela deve ser única? A objetividade científica pretendida, implica necessariamente na neutralidade do pesquisador frente à sua sociedade? A objetividade descarta os valores na Antropologia em absoluto?

O que pode estar implícito na base de todo este questionamento é a metodologia antropológica, pois, como Evans Pritchard, pensamos que fazer ciência é algo mais que um simples relato jornalístico:

"Ás vezes ouço dizer que qualquer pessoa pode esludar e escrever um livro sobre um povo primitivo. Talvez qualquer um possa, mas não vai estar necessariamente acrescentando algo à antropologia. Na ciência, como na vida, só se acha o que se procura. Não se pode ter as respostas se não se sabe quais são as perguntas. Por conseguinte, a primeira exigéncia para que se possa realizar uma pesquisa de campo é um treinamento rigoroso, para que se saiba como e o que obscrvar, $c$ o que é teoricamente significativo. É essencial perceber que os falos, $\mathrm{cm}$ si, não têm significado... Qualquer pessoa que não seja completamente idiota pode fazer trabalho de campo, e se o povo que está sendo estudado nunca o foi antes, é inevitável que se conlribua com algo original para a ciência. Mas será uma contribuição teórica ou apenas factual? Qualquer um pode trazer um fato novo; o problema é trazer uma nova idéia." (Evans-Pritchard, 1978, p. 299).

A Matriz Disciplinar da Antropologia e suas principais características, que tomamos por base, são as seguintes: ${ }^{2}$

${ }^{2}$ Cardoso de Oliveira: 1984 .

Temáticas, Campinas, 2(4):141-180, jul./de\%. 1994 


\begin{tabular}{|c|c|c|}
\hline & Intelectualidade & Empirista \\
\hline & I & II \\
\hline Sincronia & $\begin{array}{l}\text { - Escola Francesa de Sociologia. } \\
\text { - Paradigma Racionalista e em sua } \\
\text { forma moderna, Estruturalista. } \\
\text { - Abstrai o tempo de suas preocu- } \\
\text { pações. } \\
\text { - Privilegia a consciência racional. }\end{array}$ & $\begin{array}{l}\text { - Escola Britânica de Antropologia. } \\
\text { - Paradigma Empiricista ou Estru- } \\
\text { tural Funcionalista. } \\
\text { - Privilegia os estudos de campo } \\
\text { comparativos. } \\
\text { - Não se preocupam com o tempo. } \\
\text { - Psicologismo de Rivers, o que } \\
\text { mais tarde é negado. }\end{array}$ \\
\hline & IV & III \\
\hline Diacronia & $\begin{array}{l}\text { - Antropologia Interpretativa. } \\
\text { - Paradigma Hermenêutico. } \\
\text { - Interiorização do tempo pelo } \\
\text { sujeito. } \\
\text { - Contextualização do conheci- } \\
\text { mento. } \\
\text { - A posição histórica do sujeito é } \\
\text { anulada: ela é condição do } \\
\text { conhecimento. } \\
\text { - Abdica da objetividade posi- } \\
\text { tivista. } \\
\text { - Tensão entre nós e o outro. }\end{array}$ & $\begin{array}{l}\text { - Escola Histórico-Cultural. } \\
\text { - Paradigma Culturalista. } \\
\text { - A história e o tempo são resgatados } \\
\text { não de forma evolucionista, mas } \\
\text { como um estudo dinâmico da cultura. } \\
\text { - Mas esta história só é apreendida a } \\
\text { na sua exterioridade: o tempo não } \\
\text { está no sujeito mas no objeto. } \\
\text { - O sujeito está neutralizado pelo } \\
\text { método. }\end{array}$ \\
\hline
\end{tabular}

Logo de início, constatamos haver uma grande tensão entre estes paradigmas polarizadas entre os defensores da objetividade Escola Francesa de Sociologia, Estrutural-Funcionalismo e o paradigma Histórico-Cultural - e os defensores da intersubjetividade, ou seja, os hermenêutas. A objetividade na Antropologia, critério fundamental para alguns na consolidação desta ciência, de forma parecida, é defendida pelos três primeiros paradigmas. Ela é garantida, em Durkheim, pelas representaçōes coletivas da sociedade e, em Lévi-Strauss, pelas estruturas inconscientes do pensamento humano. Em Rivers, são as leis universais do psicologismo que defende e em Boas, os padrōes culturais ditados pelas diferentes culturas. 
Com qualquer destes nomes, a objetividade defendida é basicamente a mesma quando em oposição à subjetividade. A noção de objetividade está ligada à idéia da neutralidade do sujeito e à inércia de seu objeto de estudo.

Historicamente falando, o que se entende por objetividade e subjetividade é:

\begin{tabular}{|l|l|}
\hline Objetividade & Subjetividade \\
\hline - O que vem do objeto, existindo fora & - O que vem do sujeito; \\
e independente do sujeito; & - O que não possui \\
- O que é universal e válido para & valor universal; \\
todos os sujeitos ou a maioria deles; & \\
- O que é imparcial. & - O que é parcial. \\
\hline
\end{tabular}

Poderíamos tentar ilustrar esta noção dizendo que, por analogia, uma fotografia de determinada casa teria valor objetivo, enquanto que uma pintura, que um sujeito em particular fizesse desta mesma casa, teria a característica da subjetividade.

Segundo esta definição tradicional, podemos nos perguntar: será que as Ciências Sociais só são ciências na medida em que possuem a capacidade de objetividade?

Fazendo-se uma relação dos conceitos que tradicionalmente se ligam a cada um destes termos, teríamos a seguinte listagem:

\begin{tabular}{|l|l|}
\hline Objetividade & Subjetividade \\
\hline Natureza & Cultura \\
Invariável & Variável \\
Leis Gerais & Interpretações \\
Razão & Sentimento \\
Ciência & Ideologia \\
Forma & Contéudo \\
Conhecimento & Emoção \\
\hline
\end{tabular}

Temáticas, Campinas, 2(4):141-180, jul./dez. 1994 
Principalmente a noção de tempo não é muito considerada pelos defensores da objetividade, ou quando é - no caso do paradigma Histórico-Cultural - a sua colocação diz respeito apenas ao objeto de estudo. O sujeito cognoscente fica fora do tempo, como que parado, olhando a realidade que se transforma.

Ao contrário, a hermenêutica interioriza as transformaçōes históricas, tanto no que diz respeito ao sujeito quanto ao seu objeto de estudo. O pesquisador já não é mero expectador, mas sujeito ativo nesta relação.

É claro que, no tocante à objetividade do conhecimento, a tensão maior será entre o paradigma IV e os demais. O diálogo proposto, portanto, será o de fazer o contraponto da hermenêutica com os demais paradigmas.

\section{I}

A questão da objetividade no conhecimento científico sempre foi motivo, tanto para a Filosofia quanto para as ciências, de grandes discussões, por ser este um dos fundamentos principais das diferentes teorias do conhecimento. É a partir de sua aceitação ou recusa que as diferentes correntes teóricas se articulam na defesa de suas posições.

Para as ciências físicas, esta discussão está praticamente esgotada e a objetividade como critério de cientificidade é lugar comum. Por ser o mundo inanimado o seu objeto de estudo, fica mais claro para o pesquisador os limites que separam o seu ser do ser de seu objeto.

Nas ciências ditas sociais, ${ }^{3}$ campo que se constitui enquanto ciência num período relativamente recente, o problema da objetividade científica é ainda questionado. Os limites que separam o cientista de seu objeto - que passa a ser ele próprio enquanto participante de uma determinada realidade - são mais difíceis de serem constatados no sentido de que, para uns, é impossível ao sujeito que

${ }^{3}$ Também chamadas culturais, humanas ou históricas.

Temáticas, Campinas, 2(4):141-180, jul./dez. 1994 
conhece se colocar do lado de fora do mundo que pretende conhecer e, para outros, isso é possível e até mesmo necessário. Para. entendermos melhor a questão da objetividade no conhecimento é importante entendermos bem a relação sujeito-objeto.

$\mathrm{O}$ conhecimento enquanto tal é historicamente entendido como o produto necessário da relação entre sujeito cognoscente e objeto cognoscível. A condição primeira e fundamental do conhecimento de uma determinada realidade é que estejam presentes tanto um quanto outro elemento desta relação. Este é um ponto pacífico das diferentes correntes científicas. O problema se complica quando da prioridade que é dada a um destes elementos: ao sujeito (idealismo, subjetivismo) ou ao objeto (realismo ou materialismo, objetivismo).

Um dos grandes pensadores da humanidade que se preocupou em estudar as possibilidades e limites do conhecimento científico, foi o alemão Immanuel Kant (1724-1804). Na Crítica da razão pura (1980), obra dedicada especialmente a esta problemática, Kant diferencia o conhecimento empírico on a posteriori (experiências sensíveis) do conhecimento puro ou a priori (independente de qualquer experiência sensível, pois é necessário e universal). Desta forma, Kant inverte a relação sujeito-objeto, tal como era concebida na época: ao invés do conhecimento ser regulado pelo objeto da experiência, era o objeto que se regulava no ato do conhecimento (agnosticismo). Este autor define a sensibilidade como intuição, at ravés da qual os objetos são apreendidos pelo sujeito que conhece. $\Lambda$ sensibilidade é dada ao sujeito pelas impressões que ele tem do objeto e pela forma que exprime a ordem na qual estas impressões são colocadas. Estas formas da sensibilidade - o espaço e o tempo - são apriorísticas e, portanto, independem de qualquer experiência anterior. É porque possui aprioristicamente as noções de espaço e de tempo, que o sujeito cognoscente percebe os objetos que são exteriores a si mesmo, relacionando-os espacialmente e/ou temporalmente. Portanto, segundo a concepção kantiana, o fundamental para o conhecimento das coisas são as noções puras de espaço e tempo.

Temáticas, Campinas, 2(4):141-180, jul./dez. 1994 
Além da necessidade destas duas noções, Kant também reconhece outros elementos apriorísticos aos quais ele chama de categorias do entendimento. São eles: unidade, pluralidade, totalidade, realidade, negação, limitação, substância, causa, comunidade, possibilidade, existência e necessidade. Todo conhecimento precisa ser sintetizado e as categorias do entendimento, para Kant, são a maneira de viabilizar esta síntese.

De um modo geral, o importante para nós, neste momento, é entender a resposta que o kantismo dá a pergunta: o que é conhecer? Para ele, a "apercepção transcedental" seria a "pura consciência original e inalterável", ou seja, aquilo que torna possível a realidade enquanto realidade para um sujeito. Esta "apercepção" possui um caráter objetivo para Kant, no sentido de que representa a condiçāo de toda possível objetividade. Esta é uma maneira de mostrar como se constitui um objeto cognoscível.

$\mathrm{O}$ entendimento deste núcleo central da teoria do conhecimento em Kant se faz necessário para que possamos entender a proposição da objetividade na tradição racionalista e.a sua polarização com a tradição empirista, conforme a Matriz Disciplinar da Antropologia. É com Kant, por exemplo, que Durkheim dialoga todo o tempo, segundo a tradição racionalista do filósofo alemão, mas criticando a inversão sujeito-objeto que este opera no ato do conhecimento.

\section{II}

Para Durkheim, as idéias que temos acerca da realidade não podem ser confundidas com a realidade em si. Os conceitos que fazemos em relação a um determinado objeto devem ser feitos a posteriori, do contrário estes conceitos serão pura intuição impregnadas de idéias pré-concebidas e de paixões subjetivistas, que é como procede Kant, diz Durkheim. O conhecimento racional, que por esta razão é científico, opõe-se aos preconceitos e às pré-noções que, por isto mesmo, não passam de sentimentos e, portanto, não são científicas. Ao agnosticismo kantiano, Durkheim propõe o que chama realismo, 
proposta esta que vamos encontrar em sua Sociologia e também no primeiro paradigma proposto por Roberto Cardoso de Oliveira.

O primeiro ponto, e o mais importante desta teoria sociológica, é o tratamento do fato social como coisa. É entendê-lo como possuidor de uma existência exterior e independente do sujeito cognoscente. $\mathrm{O}$ vetor cognitivo, ao contrário do apriorismo kantiano, aqui se inverte:



Os fatos sociais existem na realidade concreta e a sua existência, enquanto tal, não pode ser substituída pela idéia que possamos ter desta mesma realidade. Os conceitos são necessários e importantes para a ciência em Durkheim somente na medida em que são construídos a partir da realidade que se dá a conhecer.

Se, no início de sua pesquisa, o cientista já possui uma classificação dos fatos sociais, é porque ele a obteve através de puro raciocínio lógico. A teoria científica só pode existir quando a ciência possuir o conhecimento suficiente de seu objeto de estudo.

A objetividade na teoria do conhecimento durkheimiana reside justamente neste ponto. A coisa em si, como é encontrada pelo sujeito na realidade, não deve ser modificada por ele e isto se consegue passo à passo, de forma rigorosa, seguindo-se todas as regras do método científico. O sujeito deve conhecer a realidade sem "tocála", isto é, sem transformar a sua natureza. A coisa em si, e os fatos sociais entendidos nesta perspectiva, são fixos e inertes, possuindo limites determinados.

A base do método científico proposta por Durkheim é o afastamento de toda influência que o sujeito do conhecimento possa vir a imprimir em seu objeto de estudo. Suas concepções próprias, seus preconceitos e suas paixões devem ser por isto deixadas de lado, se o que se pretende é o conhecimento científico. Como isto acontece? Qual a garantia desta objetividade proposta por Durkheim?

Temáticas, Campinas, 2(4):141-180, jul./dez. 1994 
Estudando os fatos sociais segundo a sua própria natureza. 0 primeiro passo em direção a este objetivo é a definição da coisa segundo as suas propriedades externas mais visíveis que se dão a conhecer. $O$ pesquisador deve estudá-las de maneira exaustiva, sem selecioná-las, nem discriminar nenhuma delas ao seu bel prazer.

É pelo afastamento de todas as influências subjetivas que podemos alcançar os fatos tal qual eles são. Isto acontece nas Ciências Sociais quando os fatos em si são isolados de todas as suas manifestações individuais. Um exemplo nos é dado pelo próprio Durkheim quando analisa o suicídio. O autor compara a sociedade com um organismo que possui funções repugnantes, mas necessárias a sua boa saúde, sendo o suicídio uma delas. O levantamento estatístico dos suicídios é a garantia de objetividade na Sociologia. Isto porque os algarismos expressos por estas tabelas desprende-se de toda individualidade (subjetividade) de cada caso em particular, tornando objetivos os fenômenos estudados; é o que garante Durkheim:

“... a sensação é tanto mais objetiva quanto mais fixo for o objeto ao qual se liga; pois a condição de toda objetividade é a existência de um ponto de apoio constante e idêntico, ao qual a representação se possa ligar, e que permite eliminar tudo o que ela apresenta de variável e portanto de subjetivo." (Durkheim: 1982, p. 38).

A objetividade do conhecimento é, pois, assegurada pela materialidade da coisa em si como ela se apresenta a nós.

Outra característica fundamental do fato social em Durkheim, é que ele é geral porque é coletivo e independe de nós enquanto indivíduos. São exteriores às nossas consciências individuais e não são da mesma natureza que elas, possuindo causas diferentes. Por este motivo é que os fatos sociais são exteriores aos indivíduos, pertencendo a uma ordem diversa deles. Apesar de ser formada por indivíduos, a sociedade não pode ser reduzida a eles. A consciência 
coletiva possui uma natureza própria que não é aquela das consciências individuais, não podendo assim, ser transformada pelos sujeitos individualmente. Ilustrando sua posição, Durkheim cita um exemplo que toma emprestado das Ciências Naturais:

"A dureza do bronze não figura nem no cobre, nem no estanho, nem no chumbo que serviram para formá-lo e que são corpos maleáveis ou flexiveis; figura na mistura por eles formada. A fluidez da água, suas propriedades alimentares ou outras, não existem nos dois gases de que se compõe, mas na substância complexa que formam ao se associarem." (Durkheim:1982, p. XXV).

Durkheim identifica os fatos sociais com os fenomenos da natureza pelo fato de ambos serem reais. Ambos devem, portanto, ser tratados de forma análoga, pois são determinados por leis objetivas da natureza, respeitando-se, é claro, a especificidade de cada campo em particular. Ambos requerem um tipo de conhecimento objetivo e são estudados cientificamente pela condição de objetividade que possuem. A sensação, as instituições e as vontades não são objetos da ciência. São objetos da arte. Ao conhecimento científico cabe o estudo da realidade, procurar saber o que ela é e não o que deveria ser ou o que o sujeito pensa que ela seja.

A ciência só tem sentido, em Durkheim, enquanto conhecimento que visa satisfazer necessidades vitais do homem, devendo deste modo, ser orientada pela realidade prática. As diferentes ciências, portanto, têm como objetivo a descoberta de leis gerais que se relacionam com fenomenos de uma mesma natureza.

Por ser geral, coletivo, exterior e independente dos indivíduos, o fato social possui também o poder de coerção sobre eles e este é o terceiro ponto importante da Sociologia proposta por Durkheim. Os fatos sociais são, principalmente, impostos a nós através da educação. Quando a aceitação pelo indivíduo é passiva, "a coisa flui naturalmente" e só sentimos o quanto nos são impostos, quando o rejeitamos. A pressão social sobre o indivíduo, pode variar de

Temáticas, Campinas, 2(4):141-180, jul./dez. 1994 
simples sorrisos e constrangimentos, até às formas violentas de imposição. Com o passar do tempo, a coercitividade dos fatos sociais os transformam em hábitos, dando ao sujeito a ilusão de que é ele quem os escolhe.

Nos seus estudos sobre As formas elementares da vida religiosa (1981), aliás título bem sugestivo do que apresenta Durkheim ser neste livro a sua proposta, afirma que o conhecimento religioso é a base de todos os tipos de conhecimento, inclusive o científico. $O$ autor propōe na introdução, o porquê da escolha das religiões primitivas:

"Empenhar-nos-emos em descrever a economia desse sistema com a exatidão $e$ a fidelidade que poderiam ser dadas por um elnógrafo ou um historiador. Mas nossa tarefa não se limitará a isso. A Sociologia se coloca outros problemas que a história ou a Etnografia. Ela não procura conhecer as formas antigas de civilização apenas com a finalidade de conhecê-las $e$ reconstituí-las. Mas, como toda ciência positiva, tem por objeto antes de tudo explicar uma realidade atual, próxima de nós, capaz portanto de afetar nossas idéias e nossos atos: cssa realidade é o homem e, mais especialmente, o homem de hoje, porque ninguém mais do que nós está interessado em conhecé-lo bem. Não estudaremos pois a religião mais arcaica que vai ser nosso tema, pelo único prazer de relatar suas bizarrices e singularidades. Se a tomamos como objeto de nossa pesquisa, é porque nos parece melhor do que qualquer outra para compreender a natureza religiosa do homem, isto $\dot{e}$, para revelar um aspecto essencial e permanente da humanidade." (Durkheim: 1981, pp. 147-148, grifos nossos).

$O$ pensamento que encontramos nas mais diferentes religiões pelo mundo, desempenha o mesmo papel em todas e é conseqüência das mesmas causas. Por esta razão, Durkheim diz que todas as religiōes são igualmente religiōes e podem ser comparáveis entre si. $\mathrm{O}$ autor propõe-se a estudar as primitivas, porque elas se apresentam de forma simples, despidas de toda complexidade das religiōes nossas

Temáticas, Campinas, 2(4):141-180, jul./dez. 1994 
contemporâneas. É nas religiōes primitivas que vamos encontrar a essência natural do pensamento religioso.

Ao contrário do que faz o cartesianismo e ao invés de um conceito lógico que é a proposição de Kant, Durkheim coloca no início da cadeia cognitiva uma realidade concreta. Estes elementos mais simples e essenciais que se encontram em estado de pureza nas religiōes primitivas, são permanentes e sociais, constituindo o conteúdo objetivo de todas as religiōes. As sociedades primitivas são mais homogêneas e os elementos que a compõem são fundamentais para a existência da vida em sociedade. A relação existente entre estes elementos, aparece aí de forma mais clara e é por esta razão que, segundo Durkheim, as observações etnográficas revelam tanto sobre a natureza da vida em sociedade.

A sociedade pensa através da razão e, sendo a razão condição necessária da ciência, é também condição da objetividade no conhecimento científico. A sociedade faz parte da natureza e como tal deve ser estudada. A objetividade em Durkheim deve ser buscada na realidade das coisas em si. É neste sentido que as categorias - que são de origem social - para Durkheim são construídas a posteriori. Do contrário para ele, é colocar a razão fora da natureza.

“O racionalismo imanente a uma teoria sociológica do conhecimento é pois intermediário entre o empirismo e o apriorismo clássico. Para os primeiros, as categorias são construçōes puramente artificiais; para o segundo, ao contrário, são dados naturais; para nós eles são, num certo sentido, obras de arte, mas de uma arte que imita a natureza com uma perfeição suscetivel de aumentá-la sem limite." (Durkheim: 1981, p. 159).

Como vemos, Durkheim critica também o tipo de conhecimento - chamado empirista - que afirma ser o sujeito o arquiteto dos conceitos da ciência, argumentando para isto que é contraditório afirmar ser a razão produto das manifestações individuais, já que ela é de origem social e por isto mesmo objetiva. Os conceitos são para a 
sociedade o que as idéias são para os indivíduos. Os conceitos são universais, pois são coletivos e relativamente imutáveis, conseqüentemente objetivos. Enquanto que as idéias possuem a marca das pessoas e mudam de um sujeito para o outro, estando implícito nelas a subjetividade de cada um de nós.

\section{III}

Contrapondo-se a Durkheim, que coloca a Sociologia no mesmo patamar que as Ciências Exatas quanto ao seu método de estudo porque ambas pertencem ao mundo natural, Clifford Geertz entende a Antropologia sob outro prisma. As qualidades de uma e de outra devem ser reconhecidamente colocadas de formas diferentes: enquanto que a Física encontra a sua razão de ser nas leis do mundo físico, isto é, possui a capacidade de objetividade, a Antropologia deve ser entendida como uma ciência interpretativa que visa buscar os significados culturais. Isto não quer dizer, segundo o autor, que devemos cair no extremo oposto, ou seja, no subjetivismo.
"Nunca me impressionei com o argumento de que, como é impossivel uma objetividade completa nesses assuntos (o que de fato ocorre), é melhor permitir que os sentimentos levem a melhor. Conforme observou Robert Solow, isso é o mesmo que dizer que, como é impossivel um ambiente perfeitamente asséptico, é válido fazer uma cirurgia num esgoto." (Geertz: 1978, p. 40).

Neste sentido, Geertz concorda com a perspectiva da hermenêutica que só recentemente vem sendo aplicada no campo da Antropologia, mas já tradicional no pensamento filosófico com autores como Schleiermacher, Dilthey, Heidegger e, mais recentemente, Gadamer e Paul Ricoeur.

$\Lambda$ questão da objetividade-subjetividade na hermenêutica, coloca-se de uma perspectiva singular quando comparada com as maneiras como são entendidas nos demais paradigmas da Ma-

Temáticas, Campinas, 2(4):141-180, jul./dez. 1994 
triz Disciplinar proposta por Roberto Cardoso de Oliveira. Paul Ricoeur, quando discute a presente questão nas Ciências Sociais, traça um paralelo com a Física e a Biologia, dizendo que carla uma destas ciências devem ter a objetividade que lhes convém.

Definindo a objetividade como “... aquilo que o pensamento metódico elaborou, pôs em ordem, compreendeu, e que por essa maneira pode fazer compreender". (1968, p. 23), Ricocur relaciona intimamente o que entende por objetividade e o método que emprega. Reconhecendo explicitamente esta ligação, afirma a necessidade das Ciências Sociais possuírem certa dose de subjetividade - o que Adam Schaff chama fator subjetivo - que entende ser a reflexão crítica que o pesquisador empreende em relação a sua teoria e à realidade estudada. O autor relativiza, assim, a gnoseologia que pretende, colocando o seu método, não como o único ou o mais verdadeiro, porém como mais um método - que, em sua opinião pessoal, é o que melhor dá conta da realidade - frente a uma pluralidade de outros. O conhecimento é, nesta linha, o mais aberto possível, não recusando os caminhos que lhe abre a história, nem as transformações que se operam no próprio sujeito do conhecimento e em seu objeto, quando do processo cognitivo.

A objetividade possível nas Ciencias Sociais, diz Ricoeur, é do tipo reflexiva, ou melhor ainda, filosófica, na qual o sujeito cognoscente constrói o seu objeto de estudo, tomando como base uma teoria científica que conscientemente o orienta. Esta construção do objeto é necessária, pois a explicação é parte do processo de compreensão e ao homem não é possível o conhecimento da totalidade do mundo. Daí a necessidade de seleção daquilo que mais interessa ao sujeito cognoscente.

Esta escolha ${ }^{4}$ do pesquisador é o que Ricoeur chama "julgamento de importância", onde os critérios que o fundamentam se encontram na teoria que serve de base ao sujeito. Estes critérios são

${ }^{4}$ Entendemos ser esta escolha mais social (cultural) que individual.

Temáticas, Campinas, 2(4):141-180, jul./dez. 1994 
a garantia da racionalidade científica, precedendo a teoria à própria experiência. A hermenêutica é pois, parte da tradição racionalista que vê em Kant um de seus mais altos expoentes:

“... essa subordinação das regras particulares da exegese e da filologia à problemática geral do compreender constituía uma reviravolta inteiramente análoga à que fora operada pela filosofia kantiana com referência às ciências da natureza. A este respeito, podemos afirmar que o kantismo constitui o horizonte filosófico mais próximo da hermenêutica. Como se sabe, o espirito geral da Crítica pretende inverter a relaçāo entre uma teoria do conhecimento e uma teoria do ser; devese medir a capacidade do conhecer antes de se enfrentar a natureza do ser." (Ricoeur: 1983, p. 20).

Contrariamente a todo tipo de teoria do conhecimento - entre elas o positivismo e a Sociologia durkheimiana - que iguala a objetividade pretendida na Física à objetividade nas Ciências Sociais, ${ }^{5}$ a hermenêutica tem como proposta o diálogo entre os homens e suas teorias, enquanto o positivismo não passa de um monólogo, no qual somente a "coisa" possui direito à palavra.

Este diálogo, ou melhor, esta intersubjetividade, para usar o termo dos próprios hermeneutas, nāo faz o sujeito do conhecimento escravo de seu objeto de estudo. A intersubjetividade é entendida como um tipo muito especial de objetividade, própria das Ciências Sociais e não deve ser comparada àquela alcançada na Física ou Biologia. É preciso respeitar a especificidade de cada ciência em
particular.

$\Lambda$ intersubjetividade é a prática do duvidar de si mesmo e procurar no outro, enquanto nós, o caminho da verdade, fim último de todo conhecimento científico. A intersubjetividade é o encontro com

${ }^{5}$ Para Durkheim, os fatos sociais se impõem ao observador, e este tem como tarefa apenas o seu registro, o que diz Ricoeur ser falso, tanto para as Ciências Sociais como também para as próprias Ciências Exatas.

Temáticas, Campinas, 2(4):141-180, jul./dez. 1994 
o outro: não apenas o eu, não apenas o ele, mas nós. Ao contrário do proposto por Durkheim, não visa o alcance da coisa em si ençuanto tal, mas da coisa para nós como é apreendida pelos diferentes sujeitos de diferentes realidades.

A mentira em confronto com a verdade, da mesma forma que o mal em confronto com o bem, visto pelo senso comum, não passam de uma visāo maniqueísta. Esse maniqueísmo não consegue superar aquela subjetividade que fa\% com que o indivíduo fique fechado somente sobre si mesmo. É o que Paul Ricoeur chama de "má subjetividade", 6 e a única maneira de ser controlada pelo pesquisador é que ele tome consciência de sua natureza e ação, podendo assim contorná-la.

As ciências, através dos métodos que thes são próprios, claramente explicitados pelo sujeito do conhecimento com a crítica de seu trabalho, mostram a verdade de forma não absolutizada. A verdade para a ciência não é única, permanente ou completa. Ela é um processo infinito do conhecimento científico. Na ciência, a verdade já não é manipulada, ${ }^{7}$ é sim criteriosa. $\Lambda$ verdade científica tem como objetivo o conhecimento da realidade, no caso das Ciencias Sociais a realidade humana, onde o sujeito possui por direito o papel principal. $\Lambda$ realidade, da qual Ricoeur fala, é a realidade construída pelo sujeito e da qual ele é parte fundamental.

É neste sentido que nas Ciências Sociais o pesquisador precisa ter certa afinidade com seu objeto de estudo, pois ele próprio é parte deste objeto. $A$ seleção que o sujeito faz na pluralidade inesgotável da realidade, é a seleção daquilo que mais se identifica com o seu ser, integrando um todo que também o influencia.

Retornando agora a Geertz e à Antropologia, o autor analisa esta ciência através da sua prática mais visível, a etnografia que

${ }^{6}$ Neste sentido, será que o etnocentrismo poderia ser considerado como uma "má subjetividade"?

${ }^{7}$ Não levamos em conta a má fé de algumas pessoas.

T'emáticas, Campinas, 2(4):141-180, jul./dez. 1994 
define como uma descrição densa, ${ }^{8}$ levando-nos à compreensão da Antropologia como forma de conhecimento. Esta descrição densa e consistente, nos é fornecida pela contextualização do objeto em foco, que permite ao sujeito do conhecimento situar-se frente ao outro. É quase um tipo de "linguagem" que se pretende universal, onde o pesquisador como sujeito do conhecimento nāo pode ser excluído.

As descrições que os antropólogos fazem são construídas por eles, segundo critérios científicos da Antropologia, como um tipo de conhecimento próprio de nossa cultura. O que devemos ter claro, é que estas construçōes não são as mesmas que os membros das culturas estudadas possuem de si mesmos. A Antropologia é um tipo de conhecimento inerente ao nosso mundo e suas interpretações têm sentido apenas em nosso meio. $\mathrm{O}$ objeto de estudo da ciência não pode ser confundido com o conhecimento que temos dele, bem como o mundo físico não pode ser confundido com a própria física. Esta questão deve estar bem clara para o sujeito que pretenda o conhecimento científico.

A construçāo do objeto de estudo pelo sujeito cognoscente, não implica que este seja por isso falso. 0 conhecimento pressupõe o sujeito pensante, que por sua vez pressupõe a conceitualização e a reflexão de uma determinada realidade. Esta realidade é diferente do conhecimento em si mesmo, pois este é somente uma abstração da concretude material e imaterial do mundo. Ao pensarmos uma pedra estamos abstraindo da realidade aquilo que nós, enquanto sujeitos de uma determinada cultura, entendemos ser a pedra, e isto não é colocar a pedra diretamente e concretamente em nossas cabeças. A realidade é sempre mais rica, possuindo como característica importante a sua inesgotabilidade e infinitude frente ao homem do conhecimento, este sim, finito e limitado.

\footnotetext{
${ }^{8}$ Para uma crítica à "descrição densa" proposta por Clifford Geertz, ver Michael Fischer, 1985.
}

Temálicas, Campinas, 2(4):141-180, jul./dez. 1994 
$\Lambda$ pergunta, que neste ponto Geertz nos coloca, é se esta forma peculiar de conhecimento, que é o conhecimento antropológico, póe em risco a objetividade que o qualifica como científico? A resposta é negativa para o autor. Isto quer dizer que a busca da cientilicidade na Antropologia não pode ser via objetividade, ${ }^{9}$ muito pelo contrário, a particularidade de seu objeto de estudo diferentes culturas de diferentes tempos e lugares coloca para nós a necessidade da intersubjetividade entre os homens dos diferentes mundos, e não devem ser comparados (etnocentrismo) nem hierarquizados (evolucionismo) entre si. As diferentes culturas devem ser entendidas como diferentes opções de vida em sociedade.

A Antropologia interpretativa proposta por Geertz não deseja que o antropólogo se transforme em nativo. $\dot{E}$ uma proposta que instrumentaliza o pesquisador no seu contato com o outro sem deixar que ele se esqueça do seu próprio mundo. É poder conversar com pessoas que "falem línguas" diferentes da nossa e, mesmo assim, haver, de certo modo, compreensão.

O objetivo da Antropologia não é encontrar um critério rígido para a construção de uma teoria geral da interpretação cultural. O que ela visa é a particularidade de cada cultura estudada. $\Lambda$ objetividade pretendida na Antropologia é, como diz Geert\%, uma "lógica informal da vida real", que ficou conhecida no meio desta nova $\Lambda$ ntropologia como intersubjetividade. $\Lambda$ intersubjetividade proposta pela Antropologia interpretativa, em nosso entender, é a mesma objetividade não absolutizada ou objetivação ${ }^{10}$ proposta por Adam Schaff na História.

\section{IV}

Contrariamente à tradição Racionalista, priorizada anteriormente, quando polarizamos entre o sincrônico e o diacrônico, se-

${ }^{9}$ Pelo menos no seu sentido rigido como é entendido pelo positivismo.

${ }^{10}$ Movimento infinito em direção à objetividade.

Temáticas, Campinas, 2(4):141-180, jul./dez. 1994 
gundo a Matriz Disciplinar de Roberto Cardoso de Oliveira, procuraremos trabalhar agora com a tradição Empirista.

É nosso ob jetivo, dentro do paradigma Funcional-Estruturalista, nos determos mais demoradamente no autor Evans-Pritchard por entendermos que ele é um centro de tensão constante em nossa disciplina. Ao mesmo tempo que é parte desta tradição, os caminhos deixados por Evans-Pritchard são múltiplos, seguindo-se daí diferentes direçōes. Para um melhor entendimento deste autor no interior do segundo paradigma, devemos caminhar um pouco ao lado de seus fundadores e autores mais exemplares como Rivers, Radcliffe-Brown e Malinowski.

Como vimos anteriormente, para o Racionalismo, o conhecimento do homem é possível graças à razão - é ela quem fundamentalmente diferencia os homens dos outros animais. Esta corrente do pensamento antropológico baseia-se historicamente no ideal cientificista da matemática, caracterizando-se pelo entendimento apriorístico dos conceitos e utilizando-se quase que exclusivamente do método dedutivo.

Ao contrário, o Empirismo ${ }^{11}$ possui como critério primeiro do conhecimento científico a experiência e se utiliza da indução como método prioritário. O critério de verdade científica e conseqüentemente de objetividade, estão nas experiências sensíveis do sujeito que, por sua vez, são anteriores a qualquer teorização que se possa fazer da realidade.

É nesta linha que se coloca Rivers (Cardoso de Oliveira, 1984), criando condições para o desenvolvimento da Antropologia Social britânica que surge como uma alternativa à tradição Racionalista de Durkheim. Os estudos de campo, em oposição aos estudos de

${ }^{11}$ Para Brugger, Empirismo significa filosofia da experiência. Dicionário de Filosofia - São Paulo, Editora Pedagógica e Universitária, 1977, p. 149.

Temáticas, Campinas, 2(4):141-180, jul./dez. 1994 
gabinete, tem origem em Rivers, embora, como nos conta Roberto Cardoso de Oliveira (1984), de forma bem diferente de como é atualmente entendido por nós.

Influenciado por Euken na Alemanha (Cardoso de Oliveira, 1984), o autor discorda que as leis da natureza possam ser aplicadas ao comportamento humano. Assim, Rivers tenta encontrar uma identidade própria para a $A$ ntropologia rompendo desta forma com aqueles que a entendiam como parte das Ciencias da Natureza.

Criticando o Evolucionismo e a sua conseqüente especulação progressiva da história, Rivers se aproxima do Difusionismo, mas, não conseguindo romper de forma categórica com a idéia de progresso unilinear, propōe para a $\Lambda$ ntropologia o seu método genealógico que se baseia na lógica indutiva de Stuart Mill. ${ }^{22}$ A causalidade segundo o autor, deve ser buscada nas experiencias concretas e tem como objetivo a descoberta de leis naturais, gerais e invariáveis, aos seres humanos.

$\Lambda$ pesar da negativa de Rivers de que não podemos reduzir a $\mathrm{An}$ tropologia ao fisiologismo humano, na prática é isto o que o autor fa\%. Por outro caminho chega à mesma conclusão que Durkheim acerca da questão do conhecimento. O homem fica reduzido a sua condição de animalidade e o conhecimento a uma questão de "ocularidade," como diz Bachelard (1968), isto é, a uma extensão da visão. A condição de humanidade do homem, a consciência que

${ }^{12} \Lambda$ teoria do conhecimento $\mathrm{em}$ Mill procura generalizar as experiências particulares daquilo que se entendia como semelhante: “... operação da mente por meio da qual inferimos que o conhecemos como verdadeiro para um ou mais casos particulares será verdadeiro em todos os casos que se assemelhe ao primeiro em cerlos aspectos a eles atribuiveis." (Cardoso de Oliveira: 1984, pp. 16-17). Segundo Stuart Mill, a causalidade é fator importante nas ciências e estas devem ser buscadas na experiência: "Porlanto, as leis empíricas descobertas pela observação sempre pedirão uma explicação que para Mill sempre poderá ser alcançada pela descoberta de leis da natureza, ou causais, das quais as leis empiricas seriam derivadas." (Cardoso de Oliveira: 1984, p. 19).

Temáticas, Campinas, 2(4):141-180, jul./dez. 1994 
possui de seu mundo e de si mesmo é conseqüencia. São as leis da natureza, ${ }^{13}$ apreendidas somente via experiência que dão a palavra final à ciência, constituindo assim o seu critério de cientificidade, resguardando-se com isso a objetividade como um modelo fixo e único de ciência e verdade.

Já Radcliffe-Brown, autor fundamental na construção e compreensão da Antropologia britânica, considera a sociedade como um organismo humano e, portanto, deve ser estudada pelo método das Ciências Naturais. O autor coloca-se contrário à utilização da História na Antropologia por entendê-la como pura especulação quando aplicada as sociedades primitivas. A Ilistória só pode ser tomada como referencia no momento em que objetivamente comprovada, ou seja, quando do conhecimento das leis do desenvolvimento social, o que se torna inviável em sociedades iletradas (Kuper: 1978, p.51).

$\Lambda$ alternativa de Radcliffe-Brown é o método comparativo que consegue ultrapassar as impressões intuitivas do sujeito (subjetividade) e se tornar um método objetivo, a exemplo do método utilizado pelas Ciências Naturais. Na metodologia proposta pelo autor, é necessário que se proceda comparando entre diferentes sistemas sociais como um todo, chegando-se aos universais comuns a eles e, assim, possibilitando a realização de uma classificação sistemática do todo.

$\Lambda$ especialidade de Radcliffe-Brown (1974) são os sistemas de parentesco é o seu objetivo é o estudo dos sistemas sociais feitos através das relações reais entre os indivíduos. Estas relações devem ser entendidas como relações visíveis, concretas e objetivas. ${ }^{14} \mathrm{O}$ uso do conceito de sistema indica uma lógica coerente em suas concepçoes teóricas, pois o autor define como uma unidade complexa num todo organizado, existindo uma interdependencia entre as suas partes.

\footnotetext{
${ }^{13}$ Segundo Rivers, estas leis são biológicas; segundo Durkheim, estas leis são sociais.

${ }^{14}$ No sentido do que é a "coisa" para Durkheim.
}

Temálicas, Campinas, 2(4):141-180, jul./dez. 1994 
$\mathrm{Na}$ verdade, todas as preocupações de Radcliffe-Brown giram em torno das possibilidades de uma Ciencia Natural das sociedades humanas (Melatti: 1978, p. 21), não priorizando o conceito de cultura por entender que este trata de aspectos singulares de cada povo è̀ ciência não cabe esta preocupação. Conseqüentemente, para o autor, não pode existir uma ciência da cultura e, neste sentido, as suas pesquisas são apresentadas como análises generalizadas e a forma como foram feitas - que caminho seguiu, que perguntas se fez, o que viu e o que viveu não estão explícitas em seus textos. Os princípios concluídos da análise comparativa ${ }^{15}$ são vistos por Radcliffe-Brown como verdadeiras leis universais e, portanto, naturais, garantindose assim na Antropologia a objetividade científica necessária à toda ciência.

Ao contrário da orientação dada por Radcliffe-Brown, a contribuição decisiva de Bronislaw Malinowski foi a nova ênfase que deu aos estudos de campo com o seu método da observação participante, mudando significativamente os rumos da $A$ ntropologia na época. $\Lambda$ té os nossos dias a sua influência é muito grande e a apresentação dos estudos de campo em forma de etnografia - uma exposição detalhada e totalizante da vida tribal é o que de mais característico possui a nossa disciplina.

Esta ênfase dada por Malinowski aos estudos de campo difere também daquela dada por Rivers, em dois aspectos: $11 \mathrm{~m}$ maior

${ }^{15}$ Para Radicliffe-Brown estes principios são (Melatti: 1978):

1- Princípio da unidade do grupo sibling que é o sentimento de solidariedade entre irmãos;

2- Principio da unidade do grupo de linhagem no qual os membros da mesma também compartilham sentimentos de unidade;

3- Princípio da geração onde os membros de gerações consecutivas se distanciam entre si. Isto acontece pela necessidade de socialização através da educação que exige disciplina e controle, o que é feito pelas geraçōes consecutivas àquelas que se educam.

Temáticas, Campinas, 2(4):141-180, jul./dez. 1994 
tempo de permanência entre o grupo estudado ${ }^{16}$ e o domínio da língua nativa. Para Malinowski, de forma análoga a RadcliffeBrown, as culturas formam uma totalidade porque são unidades funcionais que possuem um sentido em si mesmas. Todos os elementos que constitıem uma cultura têm funções e objetivos específicos e respondem a necessidades naturais de sobrevivência do homem. O etnólogo não deve estudar esses elementos de maneira isolada e nunca confiar nas regras e descrições de um informante nativo ${ }^{17}$ porque, segundo Malinowski, existe uma diferença entre o que as pessoas dizem e o que na realidade acontece. $O$ autor frisa também a cocrência interna dessas culturas e a sua capacidade em solucionar problemas relevantes.

Para Malinowski, a ciência se caracteriza pela sua objetividade e o tratamento que o pesquisador deve dar à apresentação dos seus resultados, a etnografia, é a sua imparcialidade e neutralidade. A Antropologia enquanto ciência não pode fugir a esta regra, a exemplo do que acontece nas Ciências Naturais. Na pesquisa de campo, após um treinamento anterior, o etnógrafo deve despir-se de seus preconceitos e pré-noções, colocando-se o mais intimamente possível em contato com os nativos. Entender a cultura do outro, sob a perspectiva que eles possuem de si mesmos, é onde reside a objetividade do conhecimento antropológico para Malinowski.

Mas, apesar de fazer parte de uma tradição objetivista nas ciências, de um lugar e tempo determinados, em nosso entender, esta mudança de ênfase no tratamento do objeto é significativa e esclarecedora de uma mudança de rumo que propiciou uma auto-crítica posterior da objetividade como critério de cientificidade na Antropologia, proporcionando uma nova substância às Ciências Sociais que não aquela tida como modelo nas Ciências Físicas e Biológicas. Nesta nova postura, o objeto das Ciências Sociais é tratado de

${ }^{16}$ Para Evans-Pritchard, o ideal são dois anos no campo.

${ }^{17} \mathrm{O}$ que seria mais um motivo para o aprendizado da lingua. 
uma maneira diferenciada, onde as suas principais características não podem e não devem ser esquecidas ou relegadas a um segundo plano: a vida que propicia a consciencia de si e dos demais, isto é, a consciência da alteridade.

Ao ler a introdução do livro Os Nuer $^{18}$ (1978), quando EvansPritchard coloca os objetivos a que se propōe, é difícil para nós nāo identificá-lo com o paradigma Funcional-Estruturalista da Matri\% Disciplinar de Roberto Cardoso de Oliveira. O privilegiamento que dá aos estudos de campo, o distanciamento entre o antropólogo e seu objeto, a necessidade rígida de um informante, são pontos bem familiares ao Funcional-Estruturalismo britânico. No decorrer do livro, a impressão se modifica um pouco, principalmente no capítulo $\mathrm{V}$, quando o autor faz toda uma construção de tempo e espaço, como estes conceitos são entendidos pelos próprios Nucr, "traduzindo-os" para a nossa cultura. Mas a primeira impressão é a que sobressai.

No apêndice IV à edição brasileira, resumida pela Zahar, de Bruxaria, oráculos e magia entre os Azande (1978) - "Algumas Reminiscências e Reflexões sobre o Trabalho de Campo" - nos supreendemos quando já não podemos mais fazer a identificação do autor com o paradigma em questão. Sentimos um ar de família com a Antropologia interpretativa de nossos dias ao ler as Reminiscências, passando a ligar o nome de Evans-Pritchard com algumas das mais sérias críticas feitas ao Funcionalismo e ao Estruturalismo.

Segundo Clifford Geertz (1989: 73-74), os textos construídos por Evans-Pritchard são verdadeiras fotografias antropológicas pois o autor “...constrói representações visualizáveis dos fenômenos culturais" e a narrativa transparece viva e atuante. Com uma fascinante figura de linguagem, Geertz afirma que Evans-Pritchard entende a etnografia como uma "lanterna mágica" que tem como propósito

${ }^{18}$ Pesquisa feita entre 1930 e 1935 e escrita em 1940.

Temáticas, Campinas, 2(4):141-180, jul./dez. 1994 
demonstrar que as nossas capacidades como seres humanos (o que temos em comum) são suficientes para a compreensão dos marcos sociais estabelecidos pelos "outros".

Ao contrário do pensamento durkheimiano, Evans-Pritchard entende o conhecimento científico como parte da seleção feita pelo sujeito cognoscente na realidade, relativizando a neutralidade do pesquuisador, além de entender como necessário e fundamental, uma teorização anterior a qualquer estudo de campo que por si só nada
acrescenta à ciência.
"Costumava-se dizer - e ainda se costuma fazê-lo - que o an- tropólogo vai para o campo com idéias pré-concebidas sobre a natureza das sociedades primitivas, e que suas observações um vício e não uma virtude... É também claro que as ob- teóricos o que simplesmente quer dizer que ele está ciente das várias hipóteses permitidas pelo conhecimento disponivel e que, se seus dados o permilirem, vai teslar essas hipóteses. Como poderia ser diferente? Não se pode estudar nada sem uma teoria... Por outro lado, o antropólogo deve seguir o que encontra na sociedade que escolheu estudar: a organização
social, os valores $\mathrm{c}$ os sentimentos do povo, $\mathrm{c}$ assim por dian- social, os valores e os sentimentos do
te." (Evans-Pritchard: 1978, p. 300).

Sobre o papel do pesquisador na observação participante e mais precisamente na proposição malinowskiana do cientista "lransformar-se em nativo" - Evans-Pritchard reconhece não a sua inutilidade, mas a dificuldade real desta proposta. $O$ autor defende que o melhor para o conhecimento científico e a pesquisa de campo é que o antropólogo seja honesto, continuando a ser ele mesmo, isto é, diferenciando-se do outro pois é assim que ele é, não podendo transformar-se em algo que nunca poderá vir a ser. Opta por seguir, então, a tradição de Malinowski, dando um salto de qualidade quando percebe que o "eu" nunca poderá tornar-se o "outro".

Temáticas, Campinas, 2(4):141-180, jul./dez. 1994 
$\mathrm{Na}$ conferencia Marett pronunciada em 1950 sob o título " $\mathrm{A}$ Antropologia Social: Pasado y P'resente", 19 Evans-P'ritchard já deixava claros alguns pontos que of faziam diferenciar-se da $\Lambda$ ntropologia Social britânica de então. Nesta conferência o autor se preocupa em explicitar o método da Antropologia Social, pois é neste campo que diz haver as maiores divergências entre os antropólogos: diferentes maneiras de se conhecer o objeto a que se propōem.

$\mathrm{O}$ que Evans-Pritchard lança como ponto de partida de sua discussão é a questão dos métodos e objetivos da Antropologia Social. Reconhecendo a autonomia relativa da $A$ ntropologia frente às demais disciplinas - principalmente a autonomia significativa em relação às Ciências Naturais - o que em nosso entender é um marco fundamental para as Humanidades, Evans-Pritchard coloca a $\mathrm{An-}$ tropologia no campo das Ciencias Sociais, o que marca de maneira decisiva a divisão de águas entre o autor e os seus predecessores Rivers e Radcliffe-13rown.

Desde o seu nascimento, o ideal cientificista da objetividade, da neutralidade e da verdade, leva alguns autores a buscar nas Ciencias da Natureza um lugar para a Antropologia. O argumento de que se utilizam é a natureza humana (biológica) que é a mesma em toda parte e em todos os tempos. Livans-Pritchard critica esta posição argumentando que aqueles que vêem na Antropologia uma Ciência Natural, levam ao entendimento do homem como um autônomo que é regido exclusivamente por leis biológicas. Além disso, critica o Evolucionismo por tentar amarrar a essas leis um desenvolvimento unilinear e necessário, tendo as sociedades que passar obrigatoriamente por etapas hierarquizadas. Estes estudos, para o autor, estavam mais preocupados com as semelhanças do que com as diferenças entre as culturas.

${ }^{19}$ Mais tarde editada juntamente com outros trabalhos em Ensayos de Antropologia Social (1978).

Temálzcas, Campinas, 2(4):141-180, jul./de\%. 1994 
Portanto, também Evans-Pritchard critica a Ilistória conjectural a exemplo de Rivers e Radcliffe-Brown, mas se afasta desses autores quando não nega a Ilistória enquanto tal e, sim, a especulação que a torna conjectural. Muito pelo contrário, o autor resgata a temporalidade das culturas sob a perspectiva do que Kuper (1978) chama historicismo.

Na aplicação do método comparativo, Evans-Pritchard afirma que o seu objetivo não foi a compreensão das instituições sociais, mas, sim, a busca de suas origens e de seu desenvolvimento. As sociedades, eram entendidas como organismos ou sitemas naturais que possuiam um desenvolvimento necessário de acordo com leis universais, gerando uma rigidez no método que se transforma em norma, o que é inconcebível nas humanidades, para o autor.

Em certo sentido concorda que as sociedades sejam entendidas como sistemas, mas os modelos construídos pelos antropólogos em suas análises, devem ser buscados na História e não nas Ciências Naturais. Assim como nos séculos XVIII e XIX a Antropologia foi marcada pela influência da História especulativa, o século XX gerou o Funcionalismo e o Difusionismo (leis psicológicas) que foram influenciados pela Psicologia.

O papel do antropólogo, deixa claro Evans-Pritchard, nāo é a descoberta de leis, ${ }^{20}$ mas a interpretação das culturas ${ }^{21}$ e a busca das estruturas básicas subjacentes as sociedades. ${ }^{22}$ Estas estruturas variam segundo o tempo e o lugar e são entendidas pelo autor como um conjunto de abstrações construídas pelo antropólogo através da análise minuciosa da cultura estudada. O antropólogo deve relacionar logicamente estas estruturas até formar um padrão ou um modelo, e desta forma ter uma visão da sociedade como um todo em seus aspectos essenciais.

\footnotetext{
${ }^{20}$ Caracteristica principal dos defensores da objetividade.

${ }^{21} \mathrm{O}$ entendimento do "outro" através de uma tradução de sua própria cultura.

${ }^{22}$ Entendimento sociológico.
}

Temálicas, Campinas, 2(4):141-180, jul./dez. 1994 
Fica bem claro para nós que o trabalho do antropólogo, segundo livans-Pritchard, se assenta sobre duas bases: um extensivo trabalho de campo onde o que se pretende é a tradução da cultura estudada visando a sua compreensão; e, através de uma análise minuciosa, construir o "modelo latente" do social, após o que se deve fazer uma comparação entre as estruturas das diferentes sociedades.

Conseqüentemente para o autor, a Antropologia Social é um tipo de historiografia ${ }^{23}$ e nela deve buscar as suas referências.

$\Lambda$ grande contribuição de Evans-Pritchard para a $\Lambda$ ntropologia moderna foi, no meu entender, a colocação desta ciência no campo das humanidades e não mais a tentativa de impor a esta disciplina os métodos específicos das Ciências Naturais. Com esta inversão de perspectiva, o autor recoloca a questão da História - de uma maneira crítica e não unilinear - entendendo como objetivo desta ciência a interpretação das culturas. No entanto - é aqui ao nosso ver que a sua ligação com o Funcional-Estruturalismo é mais forte - o autor entende como objetivo da Antropologia a busca das estruturas básicas e subjacentes das sociedades, ${ }^{24}$ reduzindo-as a um sistema, não mais natural ou orgânico, mas moral.

O importante nesta nossa reflexão é entender que lvansPritchard surge num determinado momento da história da Antropologia inglesa, formando-se dentro desta cultura científica e sofrendo influências de outras correntes. Não podemos negar também que de uma forma original Evans-Pritchard "subverte" o pensamento antropológico de sua época, dando passos surpreendentes em outras direções. O fundamental para nós é entender os caminhos que ele abriu e que estão aí, não conseguindo porém, romper de maneira decisiva com o Funcional- Lstruturalismo, o que é compreensível para um autor de seu tempo.

${ }^{23}$ Como arte de escrever a história (Evans-Pritchard: 1978, pp. 19-20).

${ }^{24}$ Que ao contrário de Lévi-Strauss variam segundo o tempo e o lugar.

Temálicas, Campinas, 2(4):141-180, jul./dez. 1994 


\section{V}

O Paradigma III da Matriz Discilinar, o que Roberto Cardoso de Oliveira chama de Escola Histórico-Cultural norte-americana, está inscrito na tradição Empiricista, mas, ao contrário do FuncionalEstruturalismo Britânico, situa-se numa linha de análise diacrônica. Recuperando o tempo, o Culturalismo reintrod uz a História em suas análises, porém de um modo diferente de como era entendida pelo Evolucionismo. Ao contrário de uma teorização geral sobre o desenvolvimento e progresso da humanidade como um todo, no Culturalismo o tempo é resgatado relacionando-se a cada grupo social, que é analisado como possuindo um desenvolvimento histórico-cultural próprio.

Franz Boas é o autor fundamental no desenvolvimento da Antropologia norte-americana. Para Alexander Lesser (1981), foi este alemão naturalizado americano quem fundou os princípios da moderna Antropologia quando passa a compreender o conceito de cultura no plural, introduzindo assim o relativismo cultural como base do pensamento antropológico moderno. Ao contrário da tradição germânico-francesa, que utilizava-se do conceito de cultura como sinônimo de civilização, ${ }^{25}$ isto é, como humanidade, erudição, arte, ciência, desenvolvimento e progresso, Franz Boas inaugurou o moderno conceito de cultura entendido como o contexto de aprendizado do comportamento humano.

Para essa mudança qualitativa no conceito de cultura e conseqüentemente na metodologia e teoria antropológica, foi fundamental em Boas a sua formação em Geografia e o seu interesse pela História Natural. A expedição ao Ártico que o trouxe para a $\Lambda$ mérica e que demonstrou a importância da observação in loco nesta área do conhecimento, foi o que propiciou ao autor perceber que o ambiente natural é determinante no comportamento dos indivíluos e em conseqüência também na cultura.

${ }^{25} \mathrm{~A}$ tradição alemã distinguia entre naturvölker e kulturvölker.

Temáticas, Campinas, 2(4):141-180, jul./dez. 1994 
Boas não estava interessado em descobrir uma Teoria Geral da Cultura e, sim, em saber o porque dessas culturas se diferenciarem tanto entre si, apesar de sabermos que possuímos todos a mesma natureza (Lesser: 1981). O autor estava mais preocupado em observar as diferenças entre os povos e refletir sobre o desenvolvimento histórico-cultural de cada um deles, com o intuito de poder comparar os diferentes modos de vida e concluir o que é universal na natureza do homem. Este objetivo do autor foi facilitado pela prática da observação, coleta e análise proporcionada pela sua experiência anterior com a História Natural e a Geografia.

Conseqüentemente, Boas conseguiu romper com o esquema Evolucionista que incluía numa mesma linha o desenvolvimento e a história de todos os povos do mundo, inaugurando no pensamento Antropológico o interesse pelo específico e pelo particular. É o reconhecimento de que o "outro" também possui uma história e de que esta história é diferente da nossa. Os antropólogos, para Boas, portanto, tem como objetivo buscar as regularidades na conduta humana porque, apesar da existência da história, que é responsável pelas transformações no tempo, estas mudanças só ocorrem dentro de padrōes determinados por cada cultura em particular. A Antropologia, então, deve se preocupar também com o tempo e com as transformaçōes culturais, mas na medida em que nos faz perceber e entender o que é permanente a cada uma destas culturas.

$\Lambda$ experiencia de Boas com a História Natural ensinou ao autor também que os dados antropológicos demonstram que devemos respeitar as diferentes culturas e tentar compreendê-las a partir delas próprias. Assim, a Antropologia Cultural nasceu de uma ciência indutiva, a História Natural, como um conhecimento aplicado aos problemas do homem no seu dia-a-dia, procura entender os indivíduos e as suas culturas como parte dos fenomenos naturais do mundo.

É a partir da primeira geração de alunos de Boas que esta $\Lambda$ ntropologia se consolida e onde podemos entender melhor a questão da objetividade no Paradigma Histórico-Cultural. Começa-se a falar

Temáticas, Campinas, 2(4):141-180, jul./dez. 1994 
mais em aculturação do que em difusão enfatizando-se a historicidade, a pluralidade, o comportamento do individuo determinado pelo meio e o relativismo das escolhas culturais. Tudo embasado e referendado na experiência concreta do trabalho de campo que via as sociedades primitivas como verdadeiros laboratórios naturais (Geertz: 1989, p. 124).

Ruth Benedict, ${ }^{26}$ uma das mais proeminentes alunas de Boas, preocupou-se em mostrar o "outro" contextualizado pelo seu próprio meio cultural, insistindo na questão de que devemos "olhar" a nós mesmos como "olhamos" para os demais. Para a autora, o que interessa à Antropologia é a cultura modelada pela sua própria tradição e o problema mais significativo a ser investigado é o dos costumes e tradições, sendo que a condição si ne qua nom de compreensão do "outro" - indivíduo e/ou cultura - é o contexto cultural que se tem como referencia.

É primordial para Ruth Benedict que o trabalho científico seja objetivo. Ser objetivo para a autora é ser relativista, isto é, compreender que o "eu" não é a referência de anạ́lise quando tratamos de culturas diferentes da nossa. O padrão cultural de cada cultura, ou seja, as normas básicas dos costumes e tradições são singularidades referentes a cada cultura e possuem nela uma permanencia notável. As transformaçōes históricas estão limitadas por estes padrões cul1 urais e são eles, no final das contas, que devem servir de indicação para a objetividade na análise.

A distância entre sujeito e objeto de estudo é o ideal perseguido pela liscola Histórico-Cultural e o conhecimento é entendido como um produto que, independe do sujeito cognoscente, é exterior a ele. Do pesquisador espera-se objetividade e neutralidade, do objeto de estudo - a cultura a verdade da vida. $A$ objetividade científica está nos padrōes culturais de cada sociedade humana, naquilo que,

${ }^{26}$ Ein O crisântemo e a cspada (1972), a autora faz um exercício de estranhamento do "eu-ocidental" com o "outro-japones", contextualizando-o dentro de sua própria cultura.

Temáticas, Campinas, 2(4):141-180, jul./de\%. 1994 
apesar das transformações históricas, permanecem culturalmente. O ideal da distância entre sujeito e objeto e, portanto, da não interferencia do pesquisador no seu objeto está presente nesta análise que se pretende neutra. Cada cultura possui a sua referencia objetivada nos seus próprios padrōes e as transformações que ocorrem serão sempre impostas pelos padrões de carla cultura em particular. O critério de verdade neste paradigma não é mais entendido como único e absoluto e a referência da análise científica já não é mais o "eu", porém o "outro", o objeto que possui vida própria e independente do sujeito cognoscente.

O conceito de relativismo cultural, fundamental no meu entender até os dias de hoje, foi a grande contribuição da Escola HistóricoCultural norte-americana para o pensamento antropológico contemporâneo. (O texto de Melville J. Ilerskovits publicado em 1948, Man and his works, the scicnce of cultural anthropology (1963), que procura delimitar as bases e o desenvolvimento da Antropologia Cultural nos Estados Unidos, é significativo na compreensão do relativismo cultural. O autor aponta como central nesta discusão a percepção de que os encontros entre os diferentes grupos humanos sempre aconteceram e sempre acontecerão. Estes encontros geram comparações que têm como consequiencia as classificações valorativas e como pano de fundo, as culturas específicas de cada um deles, que são vivenciadas além de confirmadas, nas experiências diárias de seus integrantes.

$\Lambda$ s noções de distância, peso, tempo e as demais realidades vivenciadas que nos parecem naturais e universais, para o autor estão condicionadas pela cultura, e esta, por sua vez, está condicionada pela realidade experimentada. Herskovitz defende que a cultura e a realidade são convenções traçadas consciente ou inconscientemente por um consenso do grupo. Os valores seriam, em conseqüiencia, marcos referenciais comuns que resultariam do contato entre os indivíduos de uma mesma cultura. A primeira atitude de um indivíduo pertencente a um grupo frente aos demais, seria normalmente o

Tcmáticas, Campinas, 2(4):141-180, jul./dez. 1994 
etnocentrismo, ou seja, a idéia de que "o meu modo de vida é o melhor e o mais correto" e que, portanto, tem-se a posse absoluta da verdade.

Mas, a postura relativista de IIerskovitz parece ser limitada porque em outro momento do mesmo texto, o autor defende que o etnocentrismo só pode ser superado através da razão ocidental, no caso, com a razão antropológica, apesar do seu reconhecimento de que o pensamento "primitivo" possui uma lógica própria que está fundada sobre premissas diferentes das nossas.

"Com a possível exceção dos aspéctos tecnológicos da vida, a proposição de que uma linha de pensamento ou de ação é melhor que outra é muito difícil de estabelecer sobre a base de qualquer critério universalmente aceitável." (Herskovit\%: 1963 , p. 87).

"O que o estudo comparado da cultura ensina, baseando-se no contato de primcira mäo com muitos povos, é que todos os povos pensam partindo de certas premissas que se dão por aceitas. Qualquer que seja a cadeia de arrazoados que emprega, alógica é ditada por aquelas suposições. Concedidas as premissas, a lógica é impccávcl." (Herskovitz: 1963, p.91).

() Culturalismo consegue relativiłar o "outro" em relação ao "eu" mas não consegue perceber que o "eu" enxerga o "outro" a partir de suas próprias lentes. Isto não se discute neste paradigma porque não se discute a própria ciência. Está claro para nós que aquele era um momento de formação da $\Lambda$ ntropologia, da formação de seus cânones e de seus axiomas. Hoje o momento é outro. Possuímos uma tradição e uma história consolidadas por diversas pesquisas e diferentes teorias. É o momento não da fundação mas dos questionamentos, das críticas e auto-críticas da nossa própria alteridade, da Antropologia como a ciência do conhecimento do "outro". A nossa percepção da alteridade é diferente da percepção da alteridade dos demais. E no mundo moderno é a ciência que possui o estatuto de autoridade, verdade e razão.

Temálicas, Campinas, 2(4):141-180, jul./de\%. 1994 
"No jargão dos grupos de trabalho americanos e de outras relações sociais profissionais, subsistc há muilo uma expressão: 'from where I sil'. É dila geralmente de modo meio irónico, implicando uma mudança total no ponto de vista. Quando alguém afirma com um sorriso ou um riclus de cumplicidade nos lábios: 'from where I sil', está admitindo que. ninguém percebe mais que parte da verdade. Significa que a contribuição de um sexo, uma cullura ou uma disciplina científica, que poderá mesmo fundir as árcas do sexo e da cultura, é sempre parcial e deve estar sempre à espcra da contribuição de outros para uma verdade mais total.". (Mead: 1971 , p. 36)

Margareth Mead (1971: pp. 45-46), que viveu em outro momento dessa história, levanta uma questão interessante nesta discussão: Qual a diferença entre o antropólogo e o turista ou aqueles que são obrigados ou optam por viver em uma cultura distinta da sua própria? Onde reside esta diferença? O objetivo da Antropologia para a autora reside na observação para a compreensão cultural. (Mead: 1971, p. 50)

O antropólogo para Mead não quer e não pode se tränsformar no outro, nem transformar o outro ou mesmo ser o seu porta-voz. () objetivo do antropólogo é a observação e a compreensão dos indivíduos, pois estes são reveladores de sua cultura. $\Lambda$ situação do antropólogo em meio a uma outra cultura é controlada e consciente e o resultado de seu traballo deve mostrar claramente como ele chegou àquelas afirmações o que é, emfim, o próprio processo do conhecimento antropológico. O objetivo central do antropólogo para a autora é a compreensão da cultura e o trabalho de campo precisa ser planejado e direcionado para este objetivo, sem contudo interferir na cultura estudada.

Para Mead, a única razão da Antropologia é a compreensão da cultura do "outro" (1971: p. 50) e o pesquisador deve estar preparado para render-se aos dados coletados, pois a chave para o entendimento de cada cultura está na própria cultura.

Temáticas, Campinas, 2(4):141-180, jul./dez. 1994 
$\Lambda$ autora faz uma analogia bastante interessante sobre o que é o antropólogo, aquele ser treinado entre os clássicos da disciplina e familiarizado com as diferentes culturas. 0 antropólogo para Mead, seria como um instrumento modificado que em primeiro lugar aprende como compreender as sociedades como um todo e, sem prioridades, valorizar os seus múltiplos aspectos. Também aprende, como comparar diferentes totalidades sem no entanto hierarquizalas e conseqüentemente superando os seus próprios preconceitos. $\mathrm{O}$ antropólogo é, portanto, um homem treinado para ver o mundo diferentemente de seus contemporâneos.

\section{Conclusĩo}

A teoria do conhecimento, como já foi dito, e aqui nos referimos a qualquer uma delas, se baseia na relação sujeito-objeto, que é condição primordial da existência do conhecimento enquanto tal. Deixando-se de lado um destes elementos, o conhecimento deixa de existir. Esta proposição como colocada por Durkheim, EvansPritchard e Boas, prioriza o objeto e faz dele, a bem dizer, o elemento essencial da dupla, relegando ao sujeito o papel de mero expectador da realidade. Esse sujeito, como é entendido por Durkheim, não é humano. Ele é reduzido a sua condição biológica, a sua animalidade. A capacidade de conhecimento que possui é medida pelos seus órgãos visuais que, tal qual uma câmera fotográfica, registra "imparcialmente" a realidade.

O conhecimento científico é um processo, social e infinito, que requer bastante trabalho do sujeito. Como este é parte necessária neste processo, devemos sempre levar em conta, a influência do fator subjetivo na construção do conhecimento. Não negamos a existência do objeto cognoscível como exterior e independente ao sujeito. Mas não podemos negar o papel ativo do sujeito nesta relação, transformando conscientemente a realidade na qual se esforça por compreender. Além da condição biológica, de sua carne e de seu sangue,

Tcmáticas, Campinas, 2(4):141-180, jul./dez. 1994 
o homem também possui consciência. P'ossui consciência de seu mundo, consciência de seu ser que participa e transforma o que the é exterior. () homem criou o seu mundo, criou a sua ciência e criou a si mesmo como ser humano que é. Ele transformou a sua animalidade em humanidade, nāo existindo no mundo de maneira neutra ou imparcial, não podendo o seu conhecimento, portanto, ser caracterizado como tal. O sujeito introduz algo de si no conhecimento porque este não existe isolado do homem, como que pairando sobre a sua cabeça. O conhecimento só tem sentido como existindo no interior do próprio homem. () algo de si, que o homem não pode deixar de introduzir no conhecimento, é uma das caracteristicas marcantes da ciência: a novidade que faz avançar todo conhecimento. Do contrário, o processo cognitivo seria somente reprodutivo e não essencialmente criativo. Não basta, como em Boas, considerar o objeto diacronicamente, contextualizado pelo tempo e pelo espaco determinados culturalmente. Tanto o discurso do observado como do observador devem ser contextualizados.

Isto nos tra\% de volta à problemática da objetividade na $A n$ tropologia. Segundo a hermeneutica, não podemos absolutizar o sentido da objetividade nas ('iências Sociais. Tanto que a sua proposta no final das contas, $\dot{a}$ a da intersubjetividade, uma mudansa não apenas de termos, mas de qualidade.

Mas, se esta absolutização é impossível, qual o critério mais adequado para esta objetividade não absolutizada? Mesmo que tenhamos os critérios, on até mesmo sem eles, não seria esta uma forma de subjetivizar a proposta da objetividade e cair no subjetivismo? Este é um risco que a hermenêtica, como o próprio (ieert\% concorda, corre. A sua aplicação na Antropologia é ainda muito recente e nossa expectativa é grande.

A objetividade como critério de cientificidade nas (Ciencias Sociais, e mais particularmente na $\Lambda$ ntropologia, tende ao infinito porque o conbecimento, que é social e cumulativo, constantemente se renova, aprimorando-se cada ve\% mais. Por mais esgotado que se

T'máticas, (iampinas, 2(4):141-180, jul./de\%. 1994 
diga estar um conhecimento, ele ainda será incompleto e a sua retomada em outros tempos se fará necessária. Como Weber, também acreditamos que a realidade é sempre mais rica e mais complexa do que nós a imaginamos.

Quando analisamos a construção do pensamento antropológico na história, o que nos salta aos olhos é a contribuição singular de cada autor na formulação de uma identidade própria ao conhecimento antropológico contemporâneo. Entre muitos autores e múltiplas contribuiçōes, ressaltamos neste ensaio: o pensamento de Durkheim e o seu materialismo de que o mundo social não é uma ilusão e que também possui uma objetividade própria; a contribuição de Evans-Pritchard que coloca a $A$ ntropologia no campo das Ciências Sociais, não atrelando a objetividade do mundo físico à complexidade e à dinâmica da vida humana; o relativismo cultural de Franz Boas; e a inclusão, por parte de Geertz, do sujeito cognoscente no processo do conhecimento, contextualizando tanto objeto quanto sujeito cognoscente. $O$ autor percebe que, apesar da objetividade do mundo, da complexidade da vida humana e da sua pluralidade cultural, a ciencia é um dos caminhos possíveis para a compreensão do mundo, mas não necessariamente é o único caminho possível.

Voltamos agora, após toda esta explanação, ao exemplo ilustrativo da fotografia e da pintura (objetividade-subjetividade) que citamos na introdução. Podemos dizer que também na fotografia existe a marca do sujeito que a criou - o que fica claro quando nos referimos a pintura - pois ela não pode prescindir do sujeito. É ele quem segura a câmera fotográfica ou a coloca na posição adequada, podendo assim pegar o ângulo que mais the interesse entre uma infinidade de ângulos possíveis.

$\Lambda$ ciência é apenas um dos campos possíveis para o conhecimento. $\Lambda$ Antropologia, como a ciência que busca a compreensão do "outro", é a direção seguida pelo ocidente na tomada de consciência em relação a alteridade. E no interior desta ciência, o relativismo

Temálicas, Campinas, 2(4):141-180, jul./dez. 1994 
é o salto qualitativo que consegue superar o preconceito cultural de que somos a única humanidade possível mas que não consegue ainda superar o preconceito do conhecimento científico como o mais verdadeiro e/ou como único possível.

$\Lambda$ ciencia toma ao sujeito somente $5 \%$ de "seu talento". ()s res. tantes $95 \%$ é suor, é muito trabalho. Um trabalho ao mesmo tempo solitário e ao mesmo tempo povoado por uma pluralidade de discursos, de tempos passados e presentes.

\section{BIBLIOGRAFIA}

BAC:HLARR, (iaston. O Novo Rispirto (ientifico. Rio de Janeiro: Tempo Brasilciro, 1968.

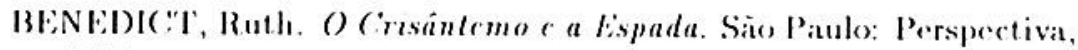
1972.

(:ARIOOSO DH: OLIVLilRA, Roberto. A "Calcgoria da Causalidade" na formaça da Antropologa. Rio de Janciro: 'Tempo Brasileiro, 1985) (Anuirio Antropológico, 1983).

. Trmpor Tradiçao: Interpetando a Antropologia. Brasilia: 'Traballo de (iencias Sociatis, Serie Antropoligicat n. 41, 1984 (UnB).

- Leiluras de Ravers. Brasilia: 'Irabalho de (iencias Sociais, Série Antropológica n. 39, 1984 (Unl3).

1)'() LIVEIRA, A rmando Mora. Wiltgenstein: Vida c Obra. Säo Paulo: Abril (ultural, 1979 (Coleção: Os Pensadores).

1)URKHEIM, Émile As Regras do Método Soczológeco. Sĩo P'iulo: ('ia. Editora Nacional, 1982.

As formas lilementares da Vida Religiosa. Sio Paulo: Ática, 1981 (Coleçio (irandes (ientistas Sociais).

Temáticas, (ampinats, 2(4):141-180, jul./de\%. 19994 
. Sociologia e Filosofia. Rio de Janeiro: Forense Universitaria, 1970 .

l'VANS-PRI'TCHAR.D. Os Nucr. São P'aulo: Perspectiva, 1978.

. Ensayos de Antmpologia Social. Buenos Aires: Siglo Veintiuno, 1978 .

- Brusaria, Oráculos e Magia entre os Azande. Rio de Janeiro: Kahar, 1978.

FISC:HER, Michael. Da Antropologia Intcrprelativa à Antropologia Crílica. Rio de Janeiro: 'Tempo) Brasileiro, 1985 (Anuário Antropológico, 1983).

(ilikirT\%, Clifford. A Interpretação das Culturas. Rio de Janeiro: Kahar, 1978.

. El Antropologo como Aulor. Mexico: Ediciones Paidos, 1989.

KAN'I, Immanuel. Crítica da Razäo Pura . Sĩo Paulo: Abril ('ultural, 1980 (Coleção: Os Pensadores).

KUPER, Adam. Antropólogos e Antropologia. Rio de Janeiro: Francisco $\Lambda$ lves, 1978.

LIMOEIRO, Miriam.O Mito do Mítodo. mimeo, s/d.

LESSER, Alexander. "Franz Boas" in: SILVERMAN, Sydel (Wditor). Totems and 'T'achers: Perspectives on the History of Anthropology New York: Columbia University P'ress, 1981.

MAIINOWSKI, Bronislaw. Os Argonaulas do Parifico Ocidental. Sĩo Paulo: Abril, 1978 (Coleçio: Os Pensadores).

MEAD, Margareth. Macho e fiemea. Vozes: Petropolis, 1971.

MELATII, Julio (ezar (org.). Radcliffe-Brown. São Paulo: Ática, 1978.

MIN'I\%, Sidney W. "Ruth Benedict" in: SILVERMAN, Sydel (Editor) Totems and Teachers: Perspectives on the History of Anthropology New York: Columbia University Press, 1981. 
PIN'T(), Álvaro Vicira. Ciéncia c lisistencia. Rio de Janciro: Pay \& Terra, 1979.

RAD('LIFFE-BROWN. "O) Fstudos dos Sistemas de Parentesco" in: Organizaģáo Social. L $\Lambda \mathrm{R} \Lambda \mathrm{I} \Lambda$, Roque de Barros (org.). Rio de Janciro: Zahar, 1974.

R.I(O) EUR, P'aul. Hestóran e Verdade. Rio de Janciro: Forense, 1968.

- Interpretaçós e Idcologas. Rio de Janciro: l'ranciseo Alves, 1983.

SCWAFF, Adam. Mistória o Verdade. Sio Paulo: Martins Fontes, 1983.

STEIN, Ernildo. Headegger: Vada e Obra. São P'aulo. Abril (ultural, 1979 (Coleçion: ()s P'ensidores).

WOLE, bric. "Alfred L. Krocber" in: SILVlirmaN, Sydel (bditor). Totems and Teachers: Perspectives on the History of Anthropology, New York: Niniversity Press, l981. 